\title{
Does left ventricular aneurysmectomy improve ventricular function in patients undergoing coronary
} bypass surgery?

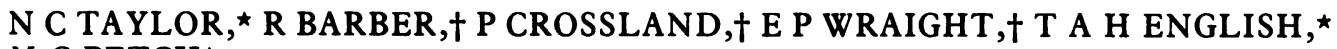 \\ M C PETCH*
}

From the Departments of ${ }^{\star}$ Cardiology and $†$ Nuclear Medicine, Papworth and Addenbrooke's Hospitals, Cambridge

SUMMARY Fourteen consecutive patients undergoing left ventricular aneurysmectomy and coronary artery bypass grafting were studied by multiple gated ventricular scintigraphy at rest and during exercise before and at six weeks and six months after surgery. All had congestive heart failure and 12 angina pectoris. Before operation left ventricular ejection fraction fell significantly with exercise, as did the regional wall motion score. Six weeks after surgery all surviving patients were free of angina, with an improvement in functional class; the total exercise workload improved significantly, but resting left ventricular ejection fraction was unchanged; the regional wall motion score improved in both the anterior and left anterior oblique projections, although extensive areas of abnormal contraction persisted. Exercise left ventricular ejection fraction improved significantly after operation at six weeks, and previous exercise induced abnormalities of regional contraction were abolished. Six months after operation angina pectoris had recurred in one patient, but there was no further change in ventricular function in the remainder.

Although resting ejection fraction is not improved, symptoms, exercise workload, and exercise ventricular function can be improved by aneurysmectomy and coronary artery bypass grafting, but the respective contribution of these two procedures remains uncertain.

Left ventricular aneurysm is a well recognised and important complication of myocardial infarction. The incidence after infarction varies widely, owing to differing diagnostic criteria but is between $2 \%$ and $15 \% .^{1-4}$ Its clinical course is variable, carrying a poor prognosis with generally a high morbidity due to angina, congestive heart failure, or atrial arrhythmias. ${ }^{56}$ Five year survival rates of between $12 \%$ and $27 \%$ have been reported, ${ }^{12}$ and the mean time from infarction to death has been quoted at 4.8 years. $^{7}$ More recent reports have shown an improved survival rate of $71 \%$ at four years; there appears to be no difference in the mortality rate between those patients with aneurysms and those without, given an equal degree of left ventricular dysfunction. ${ }^{8}$

Since Cooley et al first described the successful excision of a left ventricular aneurysm ${ }^{9}$ this operation has been widely performed in patients whose symptoms have not been adequately controlled by medical treatment. Long term symptomatic improvement

Requests for reprints to Dr N C Taylor, West Wales General Hospital, Glangwili, Carmarthen, Dyfed.

Accepted for publication 19 March 1985 after aneurysmectomy has been reported ${ }^{10-12}$ but not without an appreciable operative risk, the early mortality rate being 6-22\%.6 ${ }^{12-14}$ Despite these reports of symptomatic benefit a need exists for more objective studies of left ventricular function before and after surgery.

The purpose of our prospective study was to assess left ventricular function in a consecutive group of patients referred for elective surgery of their postinfarction aneurysm and to correlate these findings with the symptomatic state of the patient. All had multivessel coronary artery disease and underwent additional myocardial revascularisation. Patients were studied before and six weeks and six months after surgery by multiple gated ventricular scintigraphy both at rest and during dynamic supine exercise. This method provides a non-invasive, geometrically independent method of assessing serial left ventricular function.

\section{Patients and methods}

STUDY POPULATION

Fourteen consecutive patients ( 13 men, one woman; mean age 51.7 (range $38-69$ ) years) referred for elec- 
tive surgery of postinfarction left ventricular aneurysm were studied prospectively. Nine patients presented with symptoms of congestive heart failure and angina pectoris, three with angina, and two with congestive heart failure alone. No patient had detectable atrial arrhythmia or evidence of systemic embolism. Thirteen $(93 \%)$ patients had electrocardiographic or enzymatic confirmation or both of previous myocardial infarction, with a mean of 1.4 (range 1-3) infarcts per patient, the last a mean of 17.5 (range 3-60) months before investigation.

Eleven patients had severe proximal three vessel disease and 12 total occlusion of the left anterior descending coronary artery. Four patients had a $\geqslant 50 \%$ left main stem stenosis (Table 1 ). All patients had a discrete anteroapical aneurysm diagnosed by contrast angiography. This was defined as the presence of an akinetic segment outside the expected margins of the left ventricle or a localised protrusion of an area of the left ventricle outside the expected margins during systole. No patient had associated mitral regurgitation.

Medication was not withdrawn before the preoperative investigation owing to the risk of exacerbating symptoms. ${ }^{15-17}$ Table 2 shows the treatment given before and after surgery.
MULTIPLE GATED VENTRICULAR SCINTIGRAPHY Multiple gated ventriculography based on techniques previously described ${ }^{18}$ was performed at rest and during dynamic supine exercise. Imaging was started at the onset of symptoms-namely, angina, dyspnoea, fatigue, or electrocardiographic evidence of ischaemia ( $>1 \mathrm{~mm}$ ST segment depression). Blood pressure was recorded at rest and at one minute intervals throughout the exercise study; heart rate and cardiac rhythm were monitored throughout. The study was terminated if angina became progressively severe or haemodynamic deterioration or serious arrhythmia occurred. The same symptom limited protocol was repeated six weeks and six months after surgery. Data acquisition time was, on average, six minutes.

Ventricular function was assessed both in terms of global ejection fraction and abnormalities of regional contraction. ${ }^{18}$ Left ventricular wall motion was assessed in both anterior and left anterior oblique projections by reviewing the scintigraphic data in a closed loop cine format. Semiquantitative assessment was performed by dividing the left ventricle into five segments. In the anterior projection the ventricle was divided into anterobasal, anterolateral, apical, diaphragmatic, and posterobasal segments. In the oblique projection division was into proximal and distal

Table 1 Distribution and percentage stenoses of proximal coronary artery disease and number of vessels subsequently undergoing coronary bypass grafting

\begin{tabular}{|c|c|c|c|c|c|c|c|}
\hline \multirow[t]{2}{*}{ Case No } & \multicolumn{4}{|c|}{ Coronary anatomy (\% stenosis) } & \multicolumn{3}{|c|}{ Graft sites } \\
\hline & $L M S$ & $L A D$ & $C x$ & $R C A$ & $L A D$ & $C x$ & $R C A$ \\
\hline $\begin{array}{r}1 \\
2 \\
3 \\
4 \\
5 \\
6 \\
7 \\
8 \\
9 \\
10 \\
11 \\
12 \\
13 \\
14\end{array}$ & $\begin{array}{l}\overline{50} \\
= \\
= \\
= \\
\bar{z} \\
\frac{100}{50} \\
\frac{5}{50} \\
-\end{array}$ & $\begin{array}{l}100 \\
100 \\
100 \\
100 \\
100 \\
100 \\
100 \\
100 \\
-90 \\
100 \\
100 \\
90 \\
100\end{array}$ & $\begin{array}{l}75 \\
75 \\
75 \\
75 \\
75 \\
75 \\
75 \\
75 \\
75 \\
75 \\
75 \\
75 \\
75\end{array}$ & $\begin{array}{c}\text { Occluded } \\
75 \\
75 \\
75 \\
<50^{\star} \\
<50^{\star} \\
<50^{\star} \\
75 \\
75 \\
100 \\
75 \\
75 \\
75 \\
75\end{array}$ & $\begin{array}{l}1 \\
= \\
= \\
= \\
= \\
= \\
= \\
=\end{array}$ & $\begin{array}{l}\overline{2} \\
1 \\
1 \\
1 \\
1 \\
1 \\
2 \\
1 \\
1 \\
1 \\
1 \\
2 \\
-\end{array}$ & $\begin{array}{l}\frac{1}{1} \\
\frac{-}{1} \\
\frac{1}{1} \\
1 \\
\frac{1}{1} \\
\frac{1}{1}\end{array}$ \\
\hline
\end{tabular}

LMS, left main coronary artery; LAD, left anterior descending coronary artery; $\mathrm{Cx}$, circumflex system; RCA, right coronary artery. $\star$ Diffuse disease.

Table 2 Drug treatment before and after surgery in patients undergoing left ventricular aneurysmectomy and coronary bypass grafting

\begin{tabular}{|c|c|c|c|}
\hline & \multirow{2}{*}{$\begin{array}{l}\text { Before surgery } \\
(n=14)\end{array}$} & \multicolumn{2}{|l|}{ After surgery } \\
\hline & & At 6 weeks $(n=13)$ & At 6 months $(n=11)$ \\
\hline $\begin{array}{l}\text { Digoxin } \\
\text { Diuretics } \\
\text { Beta blockers } \\
\text { Calcium antagonists } \\
\text { Disopyramide } \\
\text { Warfarin } \\
\text { Long acting nitrates }\end{array}$ & $\begin{array}{l}6 \\
6 \\
8 \\
3 \\
5 \\
8\end{array}$ & $\begin{array}{r}12 \\
13 \\
1 \\
1 \\
1 \\
7 \\
-\end{array}$ & $\begin{array}{l}5 \\
9 \\
1 \\
1 \\
5 \\
\end{array}$ \\
\hline
\end{tabular}


septal, inferior, and proximal and distal posterolateral segments. Each segment was assigned a value ranging from 3 for normal contraction to 0 and -1 for akinesia and paradoxical contraction respectively. The total regional wall motion score was obtained by the summation of these segmental values in each projection.

\section{SURGERY}

Surgery was undertaken using cardiopulmonary bypass with cold cardioplegia and topical hypothermia for myocardial protection together with moderate systemic hypothermia $\left(30^{\circ} \mathrm{C}\right)$. Mean bypass time was 91.7 (range 80-109) minutes and ischaemic time 69.1 (range 48-139) minutes. At operation a discrete anteroapical aneurysm was confirmed in all 14 patients. Excision of the aneurysm was undertaken leaving a cuff of scarred fibrous tissue distal to the demarcation between normal muscle and scar tissue in order to ensure adequate suturing on closure of the resulting ventriculotomy.

All patients had coronary artery bypass grafting in addition to excision of the aneurysm. Twelve patients received grafts to the circumflex system, including eight with additional grafts to the right coronary artery (Table 1).

\section{STATISTICS}

All data are presented as arithmetic means (standard error of the mean (SEM)). Differences were tested for significance by the paired $t$ test and the Wilcoxon signed rank sum test. $P$ values $>0.05$ were regarded as not significant.

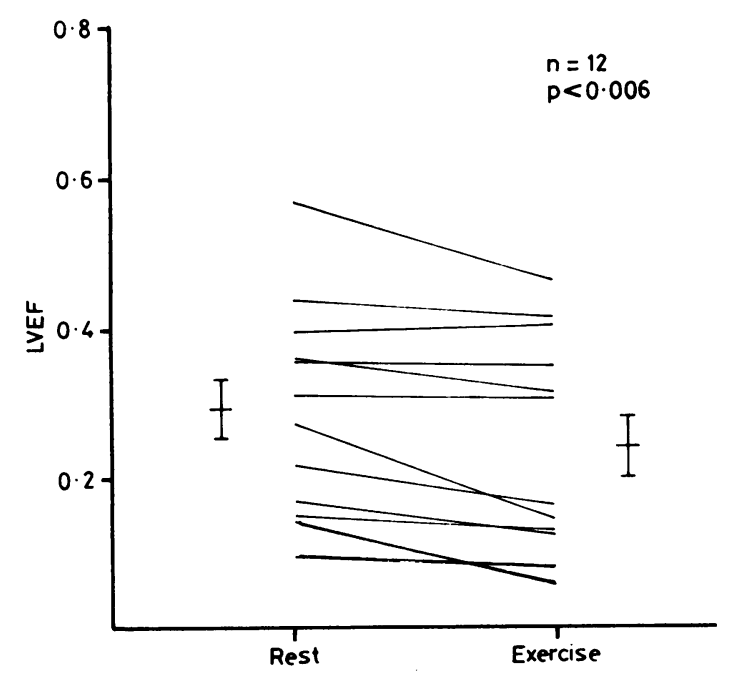

Fig. 1 Left ventricular ejection fraction (LVEF) response to exercise before left ventricular aneurysmectomy and coronary artery bypass grafting. Bars denote mean (SEM).

\section{Results}

\section{PREOPERATIVE INVESTIGATION}

Resting studies were performed in all 14 patients and exercise studies in 12. Two patients felt unable to perform the exercise study. The mean functional class (New York Heart Association criteria) ${ }^{19}$ was 3.1. Resting ejection fraction was $0.29(0.04)$. The exercise workload achieved was $1413(100) \mathrm{kpm}(230.8(16.3)$ W). Seven patients were taking beta blocking drugs; their heart rate and systolic blood pressure rose from $61 \mathrm{beats} / \mathrm{min}$ and $117 \mathrm{~mm} \mathrm{Hg}$ to 66 beats $/ \mathrm{min}$ and $118 \mathrm{~mm} \mathrm{Hg}$ respectively. Five patients were not taking beta blockers; their heart rate and systolic blood pressure rose from 87 beats/min and $112 \mathrm{~mm} \mathrm{Hg}$ to 104 beats/min and $125 \mathrm{~mm} \mathrm{Hg}$ respectively. The response to exercise in the patients before operation was abnormal, exercise ejection fraction falling to 0.24 $(0.04)(p<0.006)$ (Fig. 1), representing a relative fall in ejection fraction during exercise of $18.9(5.4) \%$. Likewise the regional wall motion score fell from 2.8 $(0.5)$ at rest, to $1.2(0.5)$ during exercise $(\mathrm{p}<0.001)$. Ten patients showed exercise induced abnormalities of regional contraction confined to the posterolateral

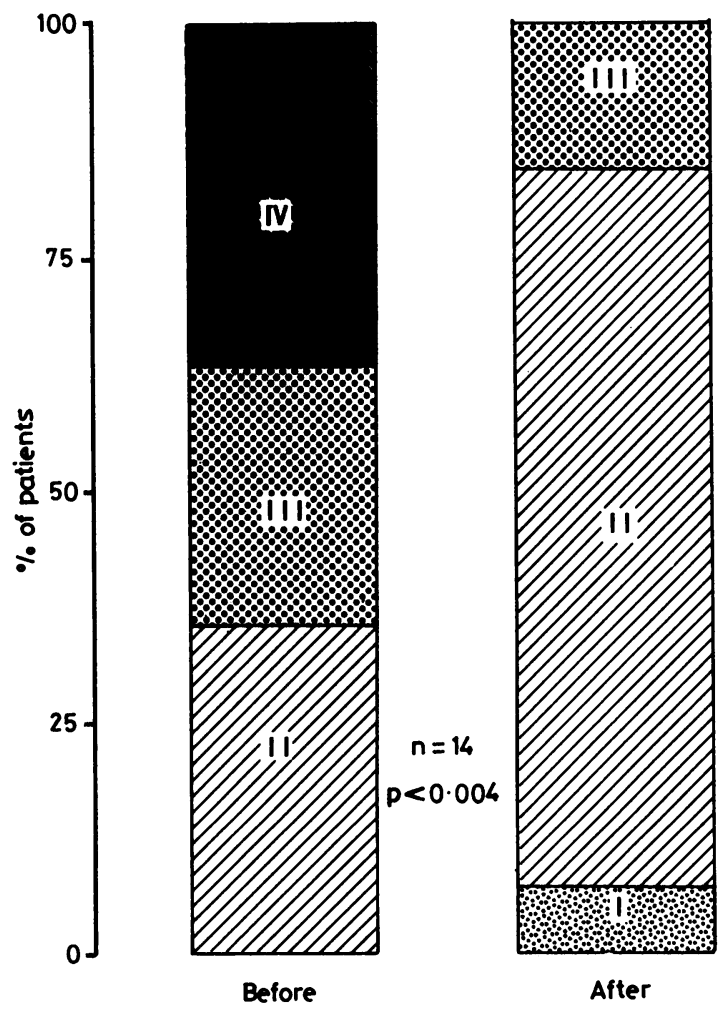

Fig. 2 Change in NYHA functional class before and after (six weeks) operation. 
wall. Two patients showed no deterioration in regional contraction during exercise but both had a fall in global ejection fraction. No serious arrhythmias were encountered during exercise.

\section{POSTOPERATIVE INVESTIGATIONS AT SIX WEEKS}

One patient died three days postoperatively of a myocardial infarction sustained during the perioperative period, giving a hospital mortality of $7 \cdot 1 \%$. All 13 survivors were available for follow up.

The mean functional class improved to $2 \cdot 1$ (p $<0.004$ ) (Fig. 2). All patients underwent an exercise study. None experienced angina but all were limited by dyspnoea and fatigue. The exercise workload improved to $2825(256) \mathrm{kpm} \quad(461.6(41.8) \mathrm{W})$ $(\mathbf{p}<0.001)$ (Fig. 3a). One patient was taking beta blockers; his heart rate and systolic blood pressure rose from 76 beats/min and $115 \mathrm{~mm} \mathrm{Hg}$ to 96 beats/min and $134 \mathrm{~mm} \mathrm{Hg}$ respectively. Twelve patients were not taking beta blockers; their heart rate and systolic blood pressure rose from 84 beats $/ \mathrm{min}$ and $118 \mathrm{~mm} \mathrm{Hg}$ to 113 beats/min and $147 \mathrm{~mm} \mathrm{Hg}$ respectively. No serious arrhythmias were encountered.

The response of the resting left ventricular ejection fraction to surgery was variable (Fig. 4(a) and (b)). As a group, however, resting ejection fraction was unchanged at $0.32(0.03)(\mathrm{NS})$. During exercise, ejection fraction increased to $0.34(0.04)(p<0.04)$ (Fig. $4(c)$ and (d)), representing a relative increase of $14 \cdot 1$ (3.2)\% compared with a preoperative fall of 18.9 $(5.4) \%$ in this group of patients $(p<0.002)$.

Resting regional wall motion score in the anterior projection improved after operation from $3 \cdot 1(0.4)$ to $6.0(0.6)(p<0.001)$, and in the oblique projection from $2.7(0.5)$ to $4.2(0.6)(p<0.001)$. Despite the apparent improvement in regional contractility extensive regional wall motion abnormalities remained after operation and were evident in both projections (Table 3 ). During exercise the previously induced abnormalities
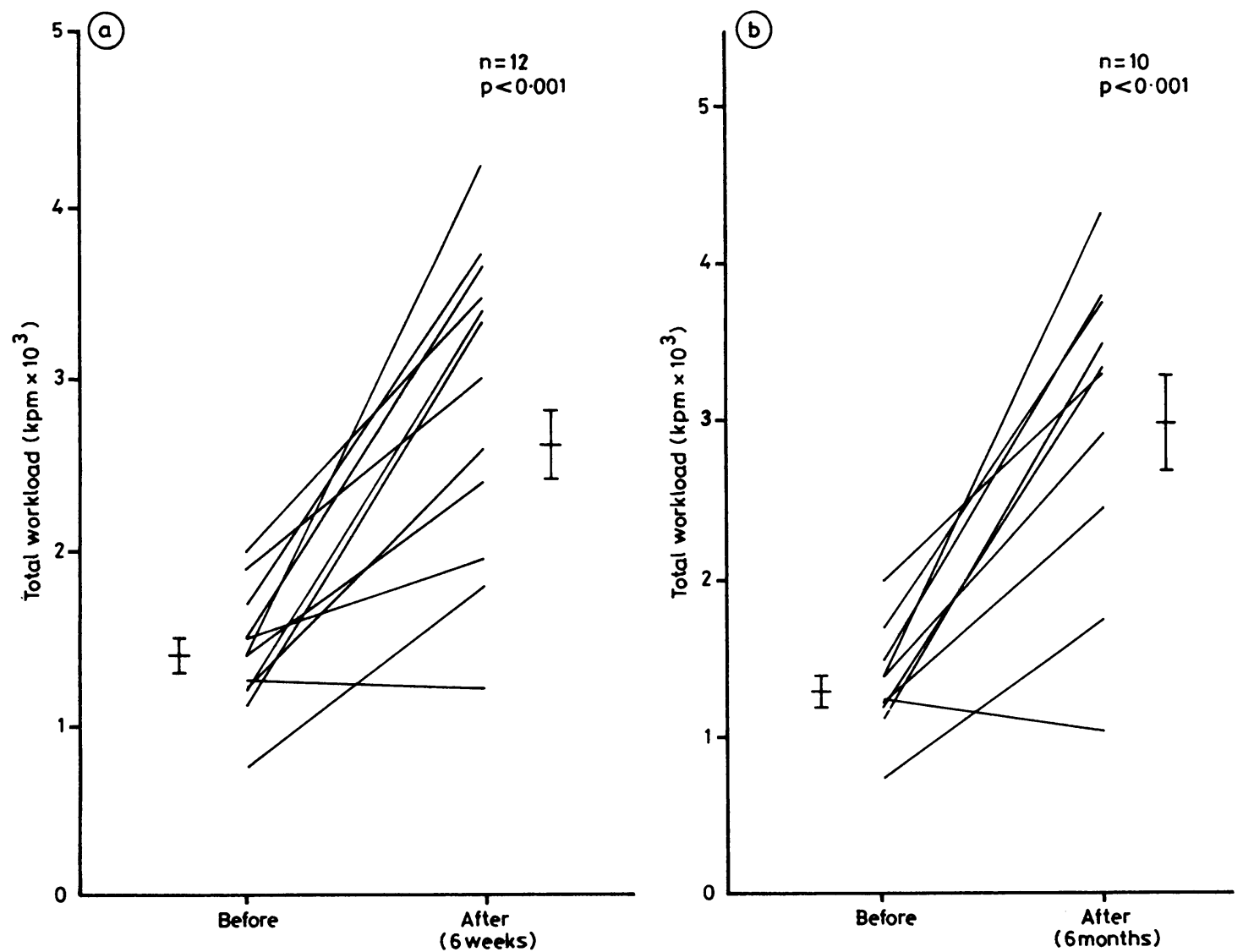

Fig. 3 Total exercise workload (a) before and six weeks after and (b) before and six months after operation. Bars denote mean $(S E M)$. Conversion: traditional to SI units-workload: $1 \mathrm{kpm} \approx 6.12 \mathrm{~W}$. 

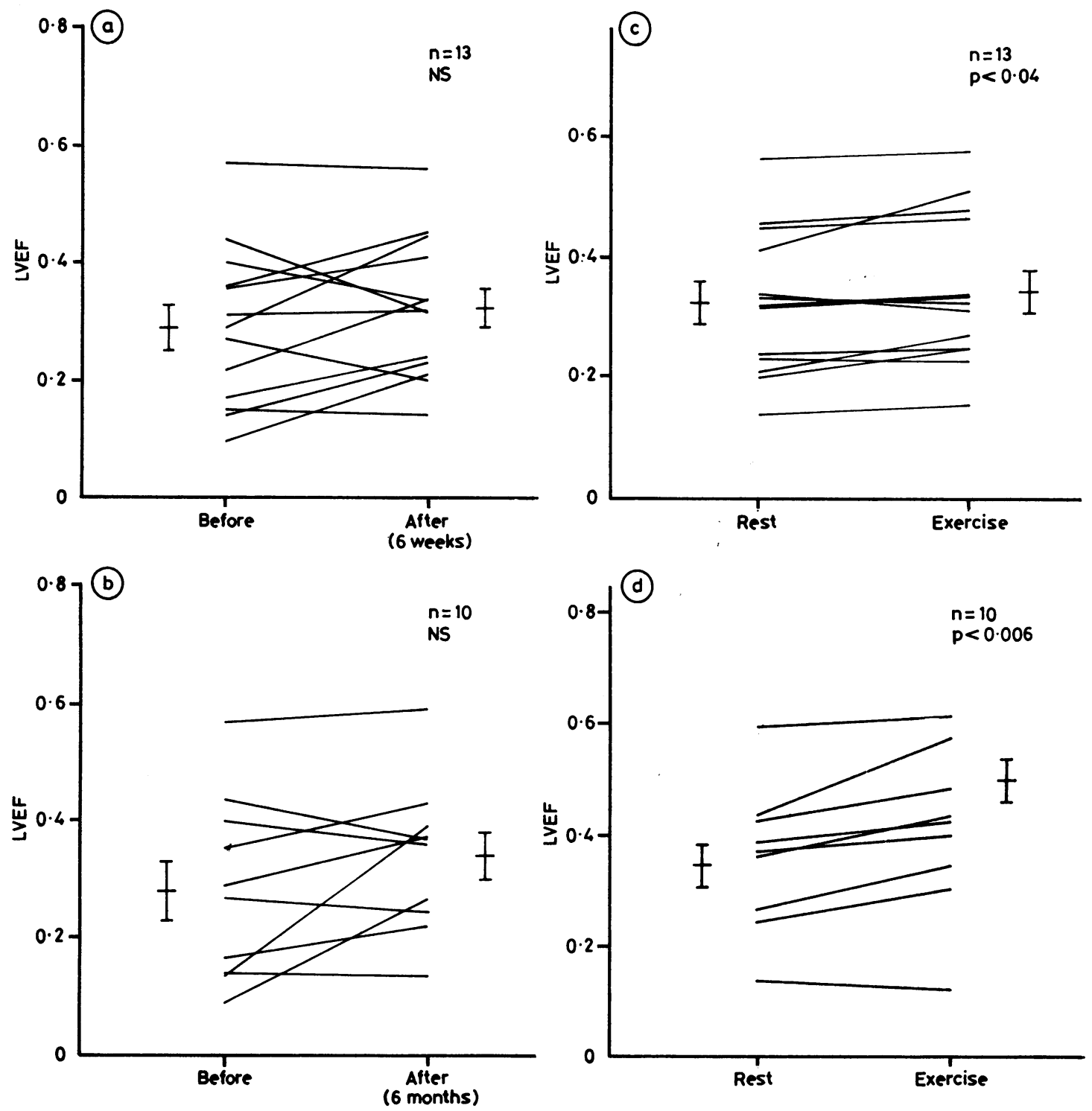

Fig. 4 Resting left ventricular ejection fraction (LVEF) (a) before and six weeks after and (b) before and six months after and left ventricular ejection fraction response to exercise (c) six weeks and (d) six months after left ventricular anewrysmectomy and coronary artery bypass grafting in surviving patients free of angina. Bars denote mean (SEM).

Table 3 Number of abnormally contracting segments remaining in surviving patients free of angina six weeks and six months after operation. Preoperative values for the same group of patients are shown in brackets

\begin{tabular}{lccc}
\hline View & \multicolumn{1}{c}{ Severe hypokinesia } & Akinesia & Paradox \\
\hline Anterior & $25(11)$ & Six weeks $(n=13)$ & $0(12)$ \\
Left anterior oblique & $15(8)$ & $16(23)$ & $1(11)$ \\
& & $30(28)$ & \\
Anterior & $22(9)$ & Six months $(n=10)$ & $9(17)$ \\
Left anterior oblique & $12(4)$ & $23(23)$ & $1(9)$ \\
\hline
\end{tabular}


of contraction were abolished, and there was no deterioration in the regional wall motion score.

\section{POSTOPERATIVE INVESTIGATIONS AT SIX}

MONTHS

At further reinvestigation six months after operation two more patients had died of further infarction, giving a mortality rate of $21.4 \%$ at six months. Of the 11 surviving patients available to follow up, 10 had no angina but were limited only by dyspnoea and fatigue. One patient had a recurrence of angina, although to a lesser extent than preoperatively. The mean functional class of the patients free of angina was unchanged.

In the group of 10 patients free of angina, although the exercise workload of 3060(343) kpm (500(56) W) showed only a small insignificant increase over the six weeks value, it remained a significant increase over that achieved before operation $(p<0.001)$ in the same group of patients (Fig. 3). One patient was taking beta blockers; his heart rate and systolic blood pressure rose from 78 beats $/ \mathrm{min}$ and $110 \mathrm{~mm} \mathrm{Hg}$ to $100 \mathrm{beats} / \mathrm{min}$ and $140 \mathrm{~mm} \mathrm{Hg}$ respectively. Ten patients were not taking beta blockers; their heart rate and systolic blood pressure rose from 75 beats/min and $119 \mathrm{~mm} \mathrm{Hg}$ to 100 beats/min and $146 \mathrm{~mm} \mathrm{Hg}$ respectively.

The response of the resting ejection fraction was again variable (Fig. 4) showing an increase in six patients and a fall in five compared with the preoperative values. As a group, however, it remained unchanged at $0.34(0.04)$ (NS).

The resting regional wall motion score in the anterior projection was $6.4(0.8)$ and in the oblique projection $4 \cdot 1(0.6)$. This represented an improvement over the preoperative values $(p<0.001)$ but no significant change from the values obtained six weeks after operation. Extensive areas of regional dysfunction still remained (Table 3).

In patients free of angina, ejection fraction during exercise increased to $0.40(0.05)(p<0.006)$ (Fig. 4), representing an $11.5(4 \cdot 6) \%$ increase in relative ejection fraction compared with a $20.9(6.9) \%$ fall in the same group of patients preoperatively $(p<0.002)$. The regional wall motion score remained unchanged during exercise, the preoperative exercise induced abnormalities having been reversed. No serious arrhythmias were encountered.

One patient experienced recurrence of angina, although clinically less severe than before operation. He maintained his improved functional class and achieved a greater exercise workload than before operation. His global left ventricular response to exercise workload was again abnormal, the ejection fraction falling from 0.31 to 0.24 during exercise, with hypokinesia developing in the posterolateral wall and a fall in the regional wall motion score. The resting ejection fraction was unchanged from the six weeks value.

\section{Discussion}

Resection of a left ventricular aneurysm has become an important form of treatment for those patients whose symptoms are not adequately controlled by medication. Many studies have reported the relief of symptoms after operation in selected cases, ${ }^{16} 14$ but few have examined serial left ventricular function and most are retrospective; for accurate evaluation of a procedure all patients undergoing surgery should be assessed prospectively. Several studies have included data at varying intervals after operation with some in the early postoperative period when adrenergic overactivity is known to influence ventricular function. ${ }^{20}$ This makes the results difficult to interpret. The results of those studies assessing left ventricular function at rest have been conflicting; some show improvement after operation 102122 while others do not. ${ }^{112324}$ Fewer studies have examined the effect of aneurysmectomy on exercise left ventricular function as judged by conventional angiography although two have shown no improvement in exercise function after operation..$^{22} 24$ In our study a prospective consecutive series of patients was evaluated at rest and during exercise by a non-invasive technique at standard time intervals after operation, the earliest being six weeks when most of the effects of surgery have worn off.

In keeping with previous studies 61012 all our patients surviving six weeks showed symptomatic improvement and a pronounced increase in exercise tolerance, which was maintained at six months after operation. During the preoperative investigation beta blocking drugs were not withdrawn because of the risk of exacerbating angina. ${ }^{15-17}$ This might have affected our results; beta blocking drugs can have a negative inotropic effect on ventricular function. ${ }^{25-27}$ In patients with ischaemic heart disease, however, these drugs have been shown to have little detrimental effect on ventricular function even in those with a low ejection fraction. ${ }^{28}$ Moreover improvement in ventricular function has been reported, ${ }^{29} 30$ as in patients with congestive cardiomyopathy. ${ }^{31}$ Thus we believe that the administration of these drugs before operation is likely to have had little influence on our results.

Resting ejection fraction remained abnormal after operation and was unchanged from the preoperative value both at six weeks and six months. Nevertheless, the individual results varied, some showing improvement and others none. This is in contrast to the study of Dymond et al, which showed an overall improvement in resting left ventricular ejection fraction after aneurysmectomy. ${ }^{22}$ Direct comparison with our study 
is difficult since Dymond's series of 12 patients included eight with single vessel disease; only two underwent myocardial revascularisation. This is in contrast to our series, most of whom presented with angina in addition to congestive failure and all of whom underwent coronary artery bypass grafting.

In theory, aneurysmectomy should reduce end diastolic and end systolic volumes equally, resulting in an increase in ejection fraction. Failure to achieve this could be due to insufficient resection of the aneurysm. The aneurysms in our patients were, however, resected to the transitional zone, leaving just a rim of fibrous scar tissue to support the sutures. An alternative suggestion is that destruction of the hypokinetic transitional zone by the sutures might render it akinctic ${ }^{23}$; this also seems implausible because it was not our surgical practice. Most probably, the failure to demonstrate an improvement in overall ejection fraction in our patients was due to the insensitivity of radionuclide ventriculography in such dilated hearts. This is quite consistent with a useful improvement in cardiac output; for example, a $33 \%$ increase in stroke volume from 45 to $60 \mathrm{ml}$ can be achieved with only a $5 \%$ increase in ejection fraction from 0.15 to 0.20 in a heart with an end diastolic volume of $300 \mathrm{ml}$. The improvement in regional contractility was largely accounted for by the resection of the paradoxically moving aneurysm (score -1 ) leaving instead an akinetic segment (score 0 ). Despite the improved wall motion score extensive areas of regional dysfunction remained and serious impairment of ventricular contraction persisted.

The improvement in exercise tolerance of those patients free of angina after operation was paralleled by an improvement in exercise ventricular function as we have reported previously. ${ }^{18}$ The deterioration in global ejection fraction induced by exercise preoperatively was corrected, although the increase was less than that expected for a normal ventricle. The exercise induced abnormalities of regional contraction were abolished after operation indicating that coronary bypass grafting corrected the ischaemic response in the remaining viable myocardium. Again direct comparison with the only two previous reports of exercise left ventricular function after aneurysmectomy ${ }^{22} 24$ is difficult. Dymond's series ${ }^{22}$ has been discussed. Froehlich et al's series, ${ }^{24}$ like ours, contained mainly patients who had multivessel disease and presented with both angina and congestive cardiac failure. Unlike our patients, all of whom underwent aneurysmectomy, only 11 of 18 patients in their series underwent resection of the aneurysmal segment; in four it was plicated and in three no discrete aneurysm was found at operation, and so no direct surgery on the ventricle was undertaken. Postoperatively only 12 of 18 patients underwent exercise evaluation of ven- tricular function, nearly a third of whom continued to experience angina with significant electrocardiographic ST segment depression. This suggests that continuing ischaemia during exercise adversely affected left ventricular function. In our series all patients at six weeks and all but one at six months were free of angina and showed no electrocardiographic evidence of ischaemia during exercise. The single patient with angina at six months was analysed separately.

Of the patients who showed preoperative evidence of reversible ischaemia, the site was localised to the posterolateral wall of the left ventricle in all cases and the wall motion abnormality was abolished by coronary grafting. This emphasises the value of radionuclide ventriculography both in assessing the functional reserve of the remaining viable myocardium and in providing information about which vessel to graft. Furthermore posterolateral wall function should be examined because it has been shown to be an important determinant of mortality associated with resection of anteroapical aneurysm. ${ }^{32}$

Many early reports stress the poor long term prognosis of medically treated patients with ventricular aneurysm but a recent long term evaluation of a large group of patients with postinfarction ventricular aneurysm $^{8}$ has shown no difference in mortality between patients with an aneurysm and those without, given an equal degree of left ventricular function. This in turn suggests that a left ventricular aneurysm has no independent influence on survival. Furthermore, the lack of improvement in resting ejection fraction after aneurysmectomy, as shown in our study, implies that operation is unlikely to improve prognosis in patients like ours.

We conclude that left ventricular aneurysmectomy performed in association with coronary artery bypass grafting confers no measurable improvement in overall resting ejection fraction as judged by radionuclide ventriculography. It is possible that global ejection fraction is not an appropriate measure of ventricular function in this group of patients and that more sensitive indices of wall motion abnormalities may show improvement, thus corroborating the clinical opinion that aneurysmectomy is of value.

Dr Crossland died recently.

\section{References}

1 Schlichter J, Hellerstein HK, Katz LM. Aneurysm of the heart: a correlative study of one hundred and two proved cases. Medicine (Baltimore) 1954; 33: 43-86.

2 Dubnow MH, Burchell HB, Titus JL. Postinfarction ventricular aneurysm: a clinicomorphologic and electrocardiographic study of 80 cases. Am Heart $\mathcal{F} 1965 ; 70$ : 753-60. 
3 Abrams DL, Edelist A, Luria MM, Miller AJ. Ventricular aneurysm. A reappraisal based on a study of sixty-five consecutive autopsied cases. Circulation 1963; 27: 164-9.

4 Mourdjinis A, Olsen E, Raphael MJ, Mounsey JPD. Clinical diagnosis and prognosis of ventricular aneurysm. Br Heart f 1968; 30: 497-513.

5 Favaloro RG, Effler DB, Groves LK, Westcott RN, Suarez E, Lozada J. Ventricular aneurysm-clinical experience. Ann Thorac Surg 1968; 6: 227-45.

6 Donaldson RM, Honey M, Balcon R, Banim SO, Sturridge MF, Wright JEC. Surgical treatment of postinfarction left ventricular aneurysm in 32 patients. Br Heart. $\mathcal{F}$ 1976; 38: 1223-8.

7 Davis RW, Ebert PA. Ventricular aneurysm: a clinicalpathologic correlation. Am F Cardiol 1972; 29: 1-6.

8 Faxon DP, Ryan TJ, Davis KB, et al. Prognostic significance of angiographically documented left ventricular aneurysm from the coronary artery surgery study (CASS). Am f Cardiol 1982; 50: 157-64.

9 Cooley DA, Collins HA, Morris GC Jr, Chapman DW. Ventricular aneurysm after myocardial infarction: surgical excision with use of temporary cardiopulmonary bypass. FAMA 1958; 167: 557-60.

10 Kitamura S, Echevarria M, Kay JH, et al. Left ventricular performance before and after removal of the noncontractile area of the left ventricle and revascularization of the myocardium. Circulation 1972; 45: 1005-17.

11 Fisher VJ, Alvarez AJ, Shah A, Dolgin M, Tice DA. Left ventricular scars. Clinical and haemodynamic results of excision. Br Heart $\mathcal{F}$ 1974; 36: 132-8.

12 Otterstad JE, Christensen O, Levorstad K, NitterHauge S. Long-term results after left ventricular aneurysmectomy. $\mathrm{Br}$ Heart $\mathcal{F}$ 1981; 45: 427-33.

13 Graber JD, Oakley CM, Pickering BN, Goodwin JF, Raphael MJ, Steiner RE. Ventricular aneurysm. An appraisal of diagnosis and surgical treatment. Br Heart $\mathcal{f}$ 1972; 34: 830-8.

14 Aranda JM, Befeler B, Thurer R, Vargas A, El-Sherif N, Lazzara A. Long-term clinical and hemodynamic studies after ventricular aneurysmectomy and aortocoronary bypass. I Thorac Cardiovasc Surg 1977; 73: 772-9.

15 Miller RR, Olson HG, Amsterdam EA, Mason DT. Propranolol-withdrawal rebound phenomenon. N Engl f Med 1975; 293: 416-8.

16 Alderman EL, Coltart DJ, Wettach GE, Harrison DC. Coronary artery syndromes after sudden propranolol withdrawal. Ann Intern Med 1974; 81: 625-7.

17 Frishman WH, Christodoulou J, Weksler B, Smithen C, Killip T, Scheidt S. Abrupt propranolol withdrawal in angina pectoris; effects on platelet aggregation and exercise tolerance. Am Heart $\mathcal{F}$ 1979; 95: 169-79.

18 Taylor NC, Barber RW, Crossland P, English TAH, Wraight EP, Petch MC. Effects of coronary artery bypass grafting on left ventricular function assessed by multiple gated ventricular scintigraphy. Br Heart $\mathcal{F}$ 1983; 50: $149-56$.
19 Criteria Committee of the New York Heart Association. Nomenclature and criteria for diagnosis of diseases of the heart and great vessels. 7th ed. Boston: Little, Brown, 1973: 296.

20 Boudoulas H, Lewis RP, Vasko JS, Karayannacos PE, Beaver BM. Left ventricular function and adrenergic hyperactivity before and after saphenous vein bypass. Circulation 1976; 53: 802-6.

21 Stoney WS, Alford WC Jr, Burrus GR, Thomas CS Jr. Repair of anteroseptal ventricular aneurysm. Ann Thorac Surg 1973; 15: 394-404.

22 Dymond DS, Stephens JD, Stone DL, Elliot AT, Rees GM, Spurrell AJ. Ccmbined exercise radionuclide and hemodynamic evaluation of left ventricular aneurysmectomy. Am Heart f 1982; 104: 977-87.

23 Sesto M, Schwarz F, Thiedemann K, Flameng W, Schlepper M. Failure of aneurysmectomy to improve left ventricular function. $\mathrm{Br}$ Heart $\mathcal{f}$ 1979; 41: 79-88.

24 Froehlich RT, Falsetti HL, Doty DB, Marcus AL. Prospective study of surgery for left ventricular aneurysm. Am F Cardiol 1980; 45: 923-31.

25 Dwyer EM Jr, Weiner L, Cox JW. Effects of betaadrenergic blockade (propranolol) on left ventricular hemodynamics and the electrocardiogram during exercise-induced angina pectoris. Circulation 1968; 38: 250-60.

26 Epstein SE, Braunwald E. Inhibition of the adrenergic nervous system in the treatment of angina pectoris. Med Clin North Am 1968; 52: 1031-9.

27 Frishman W, Smithen C, Befler B, Kligfield P, Killip T. Non-invasive assessment of clinical response to oral propranolol therapy. Am $\mathcal{F}$ Cardiol 1975; 35: 635-44.

28 Dehmer GJ, Falkoff M, Lewis SE, Hillis LD, Parkey RW, Willerson JT. Effects of oral propranolol on rest and exercise left ventricular ejection fraction, volumes, and segmental wall motion in patients with angina pectoris. Assessment with equilibrium gated blood pool imaging. Br Heart $\mathcal{F}$ 1981; 45: 656-66.

29 Battler A, Ross J, Slutsky R, Pfisterer M, Ashburn W, Froelicher V. Improvement of exercise induced left ventricular dysfunction with oral propranolol in patients with coronary heart disease. Am $\mathcal{J}$ Cardiol 1979; 44: 318-24.

30 Marshall RC, Wisenberg G, Schelbert HR, Henze E. Effects of oral propranolol on rest, exercise and postexercise left ventricular performance in normal subjects and patients with coronary artery disease. Circulation 1981; 63: 572-83.

31 Swedberg K, Hjalmarson A, Waagstein F, Wallentin I. Beneficial effects of long-term beta blockade in congestive cardiomyopathy. Br Heart $\mathcal{F}$ 1980; 44: 117-33.

32 Brawley RK, Schaff H, Stevens R, Ducci H, Gott VL, Donahoo JS. Influence of coronary artery anatomy on survival following resection of left ventricular aneurysms and chronic infarcts. F Thorac Cardiovasc Surg 1977; 73: 120-8. 